\title{
Method Validation for Preparing Urine Samples for Downstream Proteomic and Metabolomic Applications
}

\author{
Wim Ammerlaan, Jean-Pierre Trezzi, ${ }^{1,2}$ Conny Mathay, ${ }^{1}$ Karsten Hiller, ${ }^{2}$ and Fay Betsou ${ }^{1}$
}

Background: Formal validation of methods for biospecimen processing in the context of accreditation in laboratories and biobanks is lacking. A protocol for processing of a biospecimen (urine) was validated for fitness-for-purpose in terms of key downstream endpoints.

Methods: Urine processing was optimized for centrifugation conditions on the basis of microparticle counts at room temperature (RT) and at $4^{\circ} \mathrm{C}$. The optimal protocol was validated for performance (microparticle counts), and for reproducibility and robustness for centrifugation temperature $\left(4^{\circ} \mathrm{C}\right.$ vs. RT) and brake speed (soft, medium, hard). Acceptance criteria were based on microparticle counts, cystatin $\mathrm{C}$ and creatinine concentrations, and the metabolomic profile.

Results: The optimal protocol was a 20-min, $12,000 \mathrm{~g}$ centrifugation at $4^{\circ} \mathrm{C}$, and was validated for urine collection in terms of microparticle counts. All reproducibility acceptance criteria were met. The protocol was robust for centrifugation at $4^{\circ} \mathrm{C}$ versus $\mathrm{RT}$ for all parameters. The protocol was considered robust overall in terms of brake speeds, although a hard brake gave significantly fewer microparticles than a soft brake.

Conclusions: We validated a urine processing method suitable for downstream proteomic and metabolomic applications. Temperature and brake speed can influence analytic results, with $4^{\circ} \mathrm{C}$ and high brake speed considered optimal. Laboratories and biobanks should ensure these conditions are systematically recorded in the scope of accreditation.

\section{Introduction}

$\mathrm{B}$ IOSPECIMEN PROCESSING METHOD VALIDATION plays an important role in the context of quality assurance, accreditation, and biomarker development, and is a normative requirement for biobank accreditation. ${ }^{1,2}$ We present here the second in a series of articles reporting the validation of methodology for fit-for-purpose biospecimen processing for downstream applications. ${ }^{3}$ These articles propose a methodology for formal validation of biospecimen processing, saving time and resources to establish the conditions. Validation is based on reproducibility, robustness, and sample stability.

A large array of proteins are present in urine, reflecting the physiology of the kidneys, urogenital tract, and blood, making urine evaluation an integral part of clinical care and biomarker research. Urine is proving to be an increasingly useful source of metabolites and protein biomarkers for detecting disease states in both adults and neonates, ${ }^{4-7}$ as well as the effects of drugs and dietary intake on physiologic processes. ${ }^{8-10}$ Best Practices $^{11}$ and Standard Operating Procedures ${ }^{12-16}$ for routine processing and storing of biobank samples have been published.

Pellets resulting from centrifugation of urine contain cells, cell debris, sometimes bacteria, and nucleic acids (both human and microbial) that can be used for genetic analyses and diagnoses. ${ }^{17,18}$ Microparticles and exosomes, small membrane vesicles originating as membrane or internal vesicles, respectively, are secreted into the urine from nephron segments. They contain proteins, lipids, and RNA. Their protein profile may be altered in a variety of disease states, and as such can be used as a source of biomarkers. ${ }^{19}$ Exosomes (10-100 nm) represent an important source of low abundance protein biomarkers and they are isolated from urine supernatant via ultracentrifugation. Indeed, the Urinary Exosomes Protein Database (http://dir .nhlbi.nih.gov/papers/lkem/exosome/) contains more than 1200 protein sequences. Small particles in the range of $500 \mathrm{~nm}-3 \mu \mathrm{m}$ may contain bacteria, cell debris, and apoptotic bodies. High and unreproducible microparticle concentrations may affect the accuracy of proteomic applications and protein assays, ${ }^{20}$ in either the exosome-associated or exosome-independent proteome, underlining the importance of having urine samples that are relatively free of microparticles for use in biomarkers. Our objective was to obtain a urine sample as "clean" as possible from sedimenting small particles (which represent $48 \%$ of total protein in urine), but still containing the exosomal component (which accounts for $3 \%$ of total protein in urine). ${ }^{21}$ Applications based on protein and nucleic acid contents of exosomes and microparticles are not in the scope of this work.

\footnotetext{
${ }^{1}$ Integrated BioBank of Luxemburg (IBBL), Luxembourg.

${ }^{2}$ Luxembourg Centre for Systems Biomedicine (LCSB), Luxembourg.
} 
The levels of creatinine (a byproduct of muscle metabolism) and cystatin $\mathrm{C}$ (a biomarker for glomerular filtration rate) in urine are well correlated except in individuals with renal tubular damage. $^{22}$ Creatinine and cystatin $\mathrm{C}$ levels are considered a proxy for total protein concentration and they are used for categorization of urine samples for proteomics analyses, and are thus considered markers for reproducibility and robustness.

In this article, we report a methodology, including an optimization step, for preparing cell-free and debris-free urine supernatant samples. The optimal methodology was validated in terms of reproducibility and robustness, with a fit-for-purpose approach for urine preparation.

\section{Materials and Methods}

\section{Study design}

Initially, three centrifugation speeds were evaluated at room temperature $\left(\mathrm{RT}, 19^{\circ}-24^{\circ} \mathrm{C}\right)$ to assess elimination of microparticles by sedimentation. However, given that processing samples at $4^{\circ} \mathrm{C}$ minimizes degradation and possible microbial growth, centrifugation was also performed under refrigerated conditions. Optimization was determined on the basis of microparticle counts. The optimal protocol was then validated for robustness (brake speed and centrifugation temperature) and reproducibility in terms of microparticle counts, cystatin $\mathrm{C}$, and creatinine concentrations, and metabolomic output. The workflow is shown in Table 1. The study was performed in accordance with the Declaration of Helsinki (1975, revised in 2008). Urine samples were collected from healthy volunteers who provided written informed consent (CNER approval \#\#201107/02).

\section{Urine collection protocols}

Mid-stream urine samples $(100 \mathrm{~mL})$ were collected from two healthy volunteers (one male and one female, aged 35-50 years) in $125 \mathrm{~mL}$ sterile polypropylene urine collection cups (VWR, \#216-2659). Samples (20 mL for optimization, $25 \mathrm{~mL}$ for all other protocols) were transferred to $50-\mathrm{mL}$, high-performance conical tubes (VWR \#525-0158) and centrifuged in a 5810R Eppendorf centrifuge or a ThermoScientific SL40 FR centrifuge at $4^{\circ} \mathrm{C}$ within 3 hours of collection. For double centrifugation, supernatant $(13 \mathrm{~mL})$ was transferred to $15-\mathrm{mL}$ highperformance conical tubes (VWR \#252-0163). Supernatant $(10 \mathrm{~mL})$ was collected after single or double centrifugation. Samples for microparticle counting were processed immediately and the remainder transferred to $15-\mathrm{mL}$ high-performance

Table 1. Plan of Urine Aliquoting Method Optimization and Validation

\begin{tabular}{|c|c|c|c|c|c|}
\hline & Optimization 1 & Optimization 2 & $\begin{array}{l}\text { Robustness } \\
\text { (Deceleration) }\end{array}$ & $\begin{array}{l}\text { Robustness } \\
\text { (Temperature) }\end{array}$ & Reproducibility \\
\hline $\begin{array}{l}\text { Donor } \\
\text { - quantity } \\
\text { - volume }\end{array}$ & $\begin{array}{r}\text { one } \\
150 \mathrm{~mL}\end{array}$ & $\begin{array}{r}\text { two } \\
100 \mathrm{~mL}\end{array}$ & $\begin{array}{r}\text { one } \\
100 \mathrm{~mL}\end{array}$ & $\begin{array}{r}\text { one } \\
100 \mathrm{~mL}\end{array}$ & $\begin{array}{r}\text { one } \\
100 \mathrm{~mL}\end{array}$ \\
\hline $\begin{array}{l}\text { Centrifugation } \\
- \text { speed }\end{array}$ & $\begin{array}{r}\text { (D) } 2000-4000 \mathrm{~g} \\
\text { (D) } 2000-10000 \mathrm{~g} \\
\text { (D) } 2000-120000 \mathrm{~g} \\
\text { (S1) } 1000 \mathrm{~g} \\
\text { (S2) } 2000 \mathrm{~g} \\
\text { (S3) } 10000 \mathrm{~g}\end{array}$ & $\begin{array}{r}\text { (D) } 2000-12000 \mathrm{~g} \\
\text { (S) } 12000 \mathrm{~g}\end{array}$ & $12000 \mathrm{~g}$ & $12000 \mathrm{~g}$ & $12000 \mathrm{~g}$ \\
\hline - time & $\begin{array}{r}\text { (D) } 10-10 \mathrm{~min} \\
\text { (S1-S2) } 10 \mathrm{~min} \\
\text { (S3)20 min }\end{array}$ & $\begin{array}{l}\text { (D) } 10-10 \mathrm{~min} \\
\text { (S) } 20 \mathrm{~min}\end{array}$ & $20 \mathrm{~min}$ & $20 \mathrm{~min}$ & $20 \mathrm{~min}$ \\
\hline - temperature & RT & $4^{\circ} \mathrm{C}$ & $4^{\circ} \mathrm{C}$ & $\begin{array}{r}4^{\circ} \mathrm{C} \\
\mathrm{RT}\end{array}$ & $4^{\circ} \mathrm{C}$ \\
\hline - brake speed & $\begin{array}{l}\text { (D) med- hard } \\
\text { (S) med }\end{array}$ & $\begin{array}{l}\text { (D) med-hard } \\
\text { (S) med }\end{array}$ & $\begin{array}{l}\text { soft } \\
\text { med } \\
\text { hard }\end{array}$ & hard & hard \\
\hline $\begin{array}{l}\text { Transfer and mix } \\
\text { - aliquoting }\end{array}$ & $\begin{array}{r}10 \mathrm{~mL} \\
10 \times 1.0 \mathrm{~mL}\end{array}$ & $\begin{array}{r}10 \mathrm{~mL} \\
10 \times 1.0 \mathrm{~mL}\end{array}$ & $\begin{array}{r}10 \mathrm{~mL} \\
10 \times 1.0 \mathrm{~mL}\end{array}$ & $\begin{array}{r}10 \mathrm{~mL} \\
10 \times 1.0 \mathrm{~mL}\end{array}$ & $\begin{array}{r}10 \mathrm{~mL} \\
10 \times 1.0 \mathrm{~mL}\end{array}$ \\
\hline $\begin{array}{l}\text { Microparticles } \\
\text { - test frequency } \\
\text { - volume/test }\end{array}$ & $\begin{array}{l}\text { triplicate } \\
\qquad 100 \mu \mathrm{L}\end{array}$ & $\begin{array}{l}\text { triplicate } \\
100 \mu \mathrm{L}\end{array}$ & $\begin{array}{l}\text { triplicate } \\
\qquad 100 \mu \mathrm{L}\end{array}$ & $\begin{array}{l}\text { triplicate } \\
\qquad 100 \mu \mathrm{L}\end{array}$ & $\begin{array}{l}\text { triplicate } \\
\quad 100 \mu \mathrm{L}\end{array}$ \\
\hline $\begin{array}{l}\text { Cystatin C } \\
\text { - test frequency } \\
\text { - volume/test }\end{array}$ & n.d. & n.d. & $\begin{array}{r}\text { duplicate } \\
50 \mu \mathrm{L}\end{array}$ & $\begin{array}{l}\text { duplicate } \\
50 \mu \mathrm{L}\end{array}$ & $\begin{array}{r}\text { duplicate } \\
50 \mu \mathrm{L}\end{array}$ \\
\hline $\begin{array}{l}\text { Creatinine } \\
\text { - test frequency } \\
\text { - volume/test }\end{array}$ & n.d. & n.d. & $\begin{array}{r}\text { duplicate } \\
10 \mu \mathrm{L}\end{array}$ & $\begin{array}{l}\text { duplicate } \\
10 \mu \mathrm{L}\end{array}$ & $\begin{array}{l}\text { duplicate } \\
\qquad 10 \mu \mathrm{L}\end{array}$ \\
\hline $\begin{array}{l}\text { Metabolomics } \\
\text { - test frequency } \\
\text { - pre-treatment } \\
\text { - volume/test }\end{array}$ & n.d. & n.d. & $\begin{array}{r}\text { triplicate } \\
100 \mu \mathrm{L} \\
5 \mu \mathrm{L}\end{array}$ & $\begin{array}{r}\text { triplicate } \\
100 \mu \mathrm{L} \\
5 \mu \mathrm{L}\end{array}$ & $\begin{array}{r}\text { triplicate } \\
100 \mu \mathrm{L} \\
5 \mu \mathrm{L}\end{array}$ \\
\hline
\end{tabular}

n.d., not determined; (S), single centrifugation; (D), Double centrifugation. 
conical tubes, inverted five times. One-mL aliquots in 2-mL polypropylene tubes were prepared and stored at $-80^{\circ} \mathrm{C}$ for analysis of cystatin $\mathrm{C}$ and creatinine concentrations, and metabolomics. Samples evaluated at $4^{\circ} \mathrm{C}$ were kept on ice throughout processing.

\section{Centrifugation conditions}

For optimization, three centrifugation speeds were evaluated at RT (one donor, one sample per protocol): $1000 \mathrm{~g}$ and $2000 \mathrm{~g}$ (both $10 \mathrm{~min}$ with medium brake) and 10,000 $\mathrm{g}$ (20 min with hard brake). In a second step, centrifugation was evaluated at $4^{\circ} \mathrm{C}$ (two donors, one sample split between protocols), comparing a single centrifugation (12,000 $\mathrm{g}$, $20 \mathrm{~min}$ with medium brake) with a double centrifugation (2000 $\mathrm{g}, 10 \mathrm{~min}$ with medium brake, then $12,000 \mathrm{~g}, 10 \mathrm{~min}$ with hard brake). Robustness/brake speeds (one donor, one sample split into three) conditions were soft brake versus medium brake and hard brake, at $4^{\circ} \mathrm{C}, 12,000 \mathrm{~g}, 20 \mathrm{~min}$. Robustness/temperature (one donor, one sample split into two) were $4^{\circ} \mathrm{C}$ versus $21^{\circ} \mathrm{C}$, at $12,000 \mathrm{~g}, 20 \mathrm{~min}$, hard brake. Reproducibility (one donor, one sample split into three) conditions were $12,000 \mathrm{~g}, 4^{\circ} \mathrm{C}, 20 \mathrm{~min}$, hard brake.

\section{Microparticle counting}

Microparticles were counted using a CASY ${ }^{\circledR}$ TTC Measuring and Monitoring Device (Roche Applied Science) equipped with a $45 \mu \mathrm{m}$ aperture capillary, and CASY $^{\circledR}$ Measure v1.7 software, using an in-house smallparticle setup. Urine supernatant samples $(100 \mu \mathrm{L})$ at RT were added to $10 \mathrm{~mL}$ CASY-ton solution. For optimization, three $200 \mu \mathrm{L}$ sample uptakes were evaluated, plotting counts on a $10-\mu \mathrm{m}$ scale. For validation, a single $200 \mu \mathrm{L}$ uptake and a 5- $\mu \mathrm{m}$ scale were used. Events in the range of $0.67-3.00 \mu \mathrm{m}$ were considered microparticles. Counts were performed in triplicate.

\section{Creatinine and cystatin $C$ quantification}

Creatinine concentrations were determined using the Creatinine Parameter Assay Kit (R\&D Systems) and cystatin C with the Human Cystatin C Quantikine ELISA Kit
(R\&D Systems), according to the manufacturer's instructions. Briefly, urine supernatant for creatinine analysis was diluted 20-fold and treated with alkaline picrate solution (Jaffe reaction) for $30 \mathrm{~min}$ on a microtiter plate. For cystatin $\mathrm{C}$ detection, urine supernatant was used undiluted in a sandwich ELISA in a microtiter plate. Primary incubation was performed at $2^{\circ}-8^{\circ} \mathrm{C}$ for 3 hours, plates were then washed, followed by a 1-hour incubation with cystatin $\mathrm{C}$ conjugate at $2^{\circ}-8^{\circ} \mathrm{C}$. After washing, samples were incubated for $30 \mathrm{~min}$ with substrate solution at RT. Absorption was measured at $490 \mathrm{~nm}$ for creatinine and $450 \mathrm{~nm}$ for cystatin $\mathrm{C}$ using a Synergy spectrophotometer (Biotek) and test samples were compared with standard ranges. Both assays were run in duplicate on a single plate.

\section{Metabolite extraction}

Urine supernatant $(100 \mu \mathrm{L})$ was mixed with $75 \mu \mathrm{L}$ urease ( $5 \mathrm{mg} / \mathrm{mL}$, Sigma-Aldrich) and incubated for $5 \mathrm{~min}$ at $37^{\circ} \mathrm{C}$ with $400 \mathrm{rpm}$ shaking. A $5-\mu \mathrm{L}$ sample of processed urine was mixed with $45 \mu \mathrm{L}$ methanol/water (8:1), placed on a shaking device $\left(5 \mathrm{~min}, 4^{\circ} \mathrm{C}\right)$ then immediately centrifuged at $16,000 \mathrm{~g}\left(5 \mathrm{~min}, 4^{\circ} \mathrm{C}\right)$ in a $5415 \mathrm{R}$ centrifuge (Eppendorf). Supernatant $(30 \mu \mathrm{L})$ was transferred to gas chromatography glass vials and completely dried $\left(-4^{\circ} \mathrm{C}, 40 \mathrm{~min}\right)$ with a refrigerated CentriVap Concentrator (Labconco). To avoid condensation, the Concentrator was heated to RT for $15 \mathrm{~min}$ prior to vial removal. Metabolite extraction was performed in triplicate for each sample.

\section{Metabolomics GC-MS analysis}

GC-MS measurements were performed on an Agilent 6890 gas chromatograph equipped with a DB-35MS capillary column. The chromatograph was coupled to an Agilent 5975C mass spectrometer equipped with an electron impact ionization source operating at $70 \mathrm{eV}$. The spectrometer source was heated to $230^{\circ} \mathrm{C}$ and the quadrupole to $150^{\circ} \mathrm{C}$. Online metabolite derivatization was performed with a Multipurpose Sampler (Gerstel). Dried metabolite extracts were mixed with $15 \mu \mathrm{L} \mathrm{2 \%} \mathrm{methoxyamine} \mathrm{hydrochloride} \mathrm{in} \mathrm{pyridine} \mathrm{(MOX;}$ Thermo Fisher) and incubated for $30 \mathrm{~min}$ at $40^{\circ} \mathrm{C}$, then in $15 \mu \mathrm{L}$ 2,2,2-trifluoro-N-methyl-N-trimethylsilyl-acetamide

Table 2. Optimization of Urine Centrifugation Protocol, According to Microparticle Counts

\begin{tabular}{|c|c|c|c|c|c|}
\hline \multirow[b]{2}{*}{ Centrifugation Protocol } & \multicolumn{4}{|c|}{ Microparticle Counts ${ }^{\mathrm{a}}$ (counts $\left./ m L\right)$} & \multirow[b]{2}{*}{$\mathrm{p}$-value ${ }^{\mathrm{b}}$} \\
\hline & Count 1 & Count 2 & Count 3 & Mean $(S D)$ & \\
\hline \multicolumn{6}{|l|}{ Room temperature } \\
\hline $1000 \mathrm{~g}$, medium brake, $10 \mathrm{~min}$ & $9.74 \times 10^{6}$ & $8.69 \times 10^{6}$ & $9.51 \times 10^{6}$ & $9.31 \times 10^{6}\left(0.55 \times 10^{6}\right)$ & $<0.001$ \\
\hline $2000 \mathrm{~g}$, medium brake, $10 \mathrm{~min}$ & $7.10 \times 10^{6}$ & $6.97 \times 10^{6}$ & $7.73 \times 10^{6}$ & $7.27 \times 10^{6}\left(0.41 \times 10^{6}\right.$ & \\
\hline $10,000 \mathrm{~g}$, hard brake, $20 \mathrm{~min}$ & $4.67 \times 10^{6}$ & $4.46 \times 10^{6}$ & $4.64 \times 10^{6}$ & $4.59 \times 10^{6}\left(0.11 \times 10^{6}\right)$ & \\
\hline \multicolumn{6}{|l|}{$4^{\circ} \mathrm{C}$, Donor 1} \\
\hline $12,000 \mathrm{~g}$, medium brake, $20 \mathrm{~min}$ & $1.36 \times 10^{6}$ & $1.42 \times 10^{6}$ & $1.55 \times 10^{6}$ & $1.44 \times 10^{6}\left(0.10 \times 10^{6}\right)$ & 0.014 \\
\hline $\begin{array}{l}2000 \mathrm{~g}, \text { medium brake }+12000 \mathrm{~g}, \text { hard brake } \\
\quad \text { (both } 10 \mathrm{~min})\end{array}$ & $2.86 \times 10^{6}$ & $2.85 \times 10^{6}$ & $3.61 \times 10^{6}$ & $3.11 \times 10^{6}\left(0.44 \times 10^{6}\right)$ & \\
\hline \multicolumn{6}{|l|}{$4^{\circ} \mathrm{C}$, Donor 2} \\
\hline $12,000 \mathrm{~g}$, medium brake, $20 \mathrm{~min}$ & $4.89 \times 10^{5}$ & $6.14 \times 10^{5}$ & $9.17 \times 10^{5}$ & $6.73 \times 10^{5}\left(2.20 \times 10^{5}\right)$ & 0.003 \\
\hline $\begin{array}{l}2000 \mathrm{~g}, \text { medium brake }+12000 \mathrm{~g}, \text { hard brake } \\
\text { (both } 10 \mathrm{~min} \text { ) }\end{array}$ & $1.39 \times 10^{6}$ & $1.61 \times 10^{6}$ & $2.02 \times 10^{6}$ & $1.68 \times 10^{6}\left(0.32 \times 10^{6}\right)$ & \\
\hline
\end{tabular}

${ }^{\mathrm{a} R T}$ : one donor sample; $4^{\circ} \mathrm{C}$, two donors; triplicate counts for each protocol; ${ }^{\mathrm{b}}$ One-way Anova test. 
Table 3. Robustness, According to Centrifugation Deceleration

\begin{tabular}{|c|c|c|c|c|c|}
\hline \multirow[b]{2}{*}{$\begin{array}{l}\text { Evaluation parameter } \\
\text { (acceptance criteria) }\end{array}$} & \multicolumn{3}{|c|}{$\operatorname{Mean}(S D)^{\mathrm{b}}$} & \multirow{2}{*}{$\begin{array}{l}\mathrm{p}-\text { value } / \% \\
\text { NS diff. } \\
\text { metabolite } \\
\text { conc. }\end{array}$} & \multirow[b]{2}{*}{ Outcome $e^{\mathrm{d}}$} \\
\hline & $\begin{array}{l}\text { Soft brake } \\
\quad \text { (low) }\end{array}$ & $\begin{array}{l}\text { Medium brake } \\
\text { (moderate) }\end{array}$ & $\begin{array}{l}\text { Hard brake } \\
\quad \text { (fast) }\end{array}$ & & \\
\hline $\begin{array}{l}\text { Microparticle counts } / \mathrm{mL} \\
\left(<1 \times 10^{7} / \mathrm{mL}\right)\end{array}$ & $6.46 \times 10^{6}\left(1.98 \times 10^{6}\right)$ & $3.93 \times 10^{6}\left(1.21 \times 10^{6}\right)$ & $2.12 \times 10^{6}\left(0.70 \times 10^{6}\right)$ & $p=0.025$ & Rejected \\
\hline $\begin{array}{l}\text { Cystatin } \mathrm{C} \text { conc., } \mathrm{ng} / \mathrm{mL} \\
\quad(6-100 \mathrm{ng} / \mathrm{mL})\end{array}$ & $26.6(3.5)$ & 27.4 (4.7) & $27.1(1.3)$ & $p=0.976$ & Accepted \\
\hline $\begin{array}{l}\text { Creatinine conc., mg/dL } \\
\quad(12-200 \mathrm{mg} / \mathrm{dL})\end{array}$ & $70.2(0.4)$ & $69.4(0.3)$ & $67.4(1.3)$ & $p=0.078$ & Accepted \\
\hline $\begin{array}{l}\% \text { NS diff. metabolite } \\
\text { conc. }(>95 \%)\end{array}$ & & & & $97.0 \%$ & Accepted \\
\hline
\end{tabular}

$\mathrm{CV}$, coefficient of variation; NS, nonsignificant.

${ }^{a}$ Urine collection protocol: $12,000 \mathrm{~g}, 20 \mathrm{~min}, 4^{\circ} \mathrm{C} ;{ }^{\mathrm{b}}$ One donor sample measured in triplicate for microparticle counts and duplicate for cystatin $\mathrm{C}$ and creatinine; ${ }^{\mathrm{c}}$ Variation (one-way Anova) between brake speeds for microparticles, cystatin $\mathrm{C}$ and creatinine concentrations.

${ }^{\mathrm{d}}$ Based on values within acceptance criteria, NS differences between brake speeds for microparticle counts, cystatin C and creatinine concentrations, and in concentrations of $>95 \%$ metabolites (one-way Anova).

(MSTFA; Machery Nagel) for $30 \mathrm{~min}$ at $40^{\circ} \mathrm{C}$. The detector was operated in scan mode and the sampler injected $1 \mu \mathrm{L}$ of derivatized sample. The injection was set to splitless mode with helium as the carrier gas $(1 \mathrm{~mL} / \mathrm{min}$ flow rate). The gas chromatography oven was maintained at $80^{\circ} \mathrm{C}$ for $6 \mathrm{~min}$, then increased to $300^{\circ} \mathrm{C}$ (by $6^{\circ} \mathrm{C} / \mathrm{min}$ ), then to $325^{\circ} \mathrm{C}$ (by $10^{\circ} \mathrm{C} /$ $\mathrm{min}$ ), and maintained for $4 \mathrm{~min}$. GC-MS raw data was processed using the MetaboliteDetector software ${ }^{23}$ with retention index calibration enabled. Settings were: minimum number of ions $=10$; minimum peak height $=5$ noise levels; deconvolution width $=5$ scans. Samples were analyzed in triplicate. For each replicate, individual metabolite intensity was divided by the sum of all peak intensities from the sample.

\section{Validation criteria}

Robustness was evaluated in terms of brake speed (soft, medium, hard) and temperature $\left(4^{\circ} \mathrm{C}\right.$ versus RT). Acceptance criteria were: 1) microparticle counts $<1 \times 10^{7} / \mathrm{mL}$, based on previously measured ranges of urine microparticle concentrations (Ammerlaan, unpublished data); 2) cystatin C concentration 6-100 ng/mL, corresponding to reference ranges of cystatin $\mathrm{C}$ in healthy subjects; ${ }^{22} 3$ ) creatinine concentration in the undiluted samples, $12-200 \mathrm{mg} / \mathrm{dL}$, corresponding to reference ranges of creatinine in healthy subjects; ${ }^{22}$ 4) nonsignificant differences in mean microparticle counts, and creatinine and cystatin $\mathrm{C}$ concentrations; and 5) a nonsignificant difference in concentrations of $>95 \%$ of detected metabolites between different conditions.

Reproducibility acceptance criteria were: 1) microparticle counts $<1 \times 10^{7} / \mathrm{mL} ; 2$ ) cystatin C concentration $6-100 \mathrm{ng} /$ $\mathrm{mL}$; 3) creatinine concentration $12-200 \mathrm{mg} / \mathrm{dL}$; 4) CV (coefficient of variation) $<20 \%$ for mean microparticle counts, and creatinine and cystatin C concentrations; and 5) a nonsignificant difference in concentrations of detected metabolites of $>95 \%$ between replicates from a given donor.

\section{Statistical analyses}

Mean, SD, and CV were calculated using Excel. Microparticle counts, and creatinine and cystatin $\mathrm{C}$ concentrations were compared between protocols (optimization), conditions (robustness), or replicates (reproducibility) using one-way Anova tests or paired two-tailed $t$-tests. Pairwise multiple comparisons (Holm-Sidak) were performed if a significant difference was detected. For metabolomics, semi-quantitative data were obtained with batch quantification (nontargeted analysis) and statistically tested by one-way Anova and Welch's $t$-test. Significance was calculated with Sigma Plot v.12.0 (Systat Software) and R.3.0.0, with a 5\% significance threshold.

Table 4. Robustness, According to Centrifugation Temperature

\begin{tabular}{|c|c|c|c|c|c|}
\hline \multirow{2}{*}{$\begin{array}{l}\text { Evaluation parameter } \\
\text { (acceptance criteria) }\end{array}$} & \multicolumn{2}{|c|}{$\operatorname{Mean}(S D)^{\mathrm{b}}$} & \multirow{2}{*}{$\begin{array}{l}\mathrm{p}-\text { value } \mathrm{c} / \% \text { NS diff. } \\
\text { metabolite conc. }\end{array}$} & \multirow{2}{*}{$\begin{array}{l}\text { Test power } \\
(\mu=0.05)\end{array}$} & \multirow[b]{2}{*}{ Outcome $e^{\mathrm{d}}$} \\
\hline & $4^{\circ} \mathrm{C}$ & $21^{\circ} \mathrm{C}$ & & & \\
\hline $\begin{array}{l}\text { Microparticle counts } / \mathrm{mL} \\
\left(<1 \times 10^{7} / \mathrm{mL}\right)\end{array}$ & $7.56 \times 10^{6}\left(6.27 \times 10^{6}\right)$ & $4.50 \times 10^{6}\left(1.85 \times 10^{6}\right)$ & $p=0.383$ & 0.068 & Accepted \\
\hline $\begin{array}{l}\text { Cystatin C conc., ng/mL } \\
\quad(6-100 \mathrm{ng} / \mathrm{mL})\end{array}$ & $23.7(0.48)$ & $22.5(1.36)$ & $p=0.546$ & 0.093 & Accepted \\
\hline $\begin{array}{l}\text { Creatinine conc., mg/dL } \\
\quad(12-200 \mathrm{mg} / \mathrm{dL})\end{array}$ & $52.1(2.3)$ & $47.3(0.3)$ & $p=0.184$ & 0.212 & Accepted \\
\hline $\begin{array}{l}\% \text { NS diff. metabolite } \\
\text { conc. }(>95 \%)\end{array}$ & & & $99.4 \%$ & & Accepted \\
\hline
\end{tabular}

$\mathrm{CV}$, coefficient of variation; NS, nonsignificant.

${ }^{\mathrm{a}}$ Urine collection protocol: $12,000 \mathrm{~g}, 20 \mathrm{~min}$, hard brake; ${ }^{\mathrm{b}}$ One donor sample measured in triplicate for microparticle counts and duplicate for cystatin $\mathrm{C}$ and creatinine; ${ }^{\mathrm{c}}$ Variation (paired t-test) between temperatures for microparticles, cystatin $\mathrm{C}$ and creatinine concentrations; ${ }^{\mathrm{d}}$ Based on values within acceptance criteria, NS differences between temperatures for microparticle counts, cystatin C and creatinine concentrations, and in concentrations of $>95 \%$ metabolites (one-way Anova). 


\section{Results}

\section{Optimization of urine processing protocol}

Microparticle counts were determined for three centrifugation protocols at RT (Table 2). Significant differences in microparticle counts were reported between the three protocols $(p<0.001)$ in Anova one-way tests and between all combinations in pairwise multiple comparisons, with higher centrifugation speeds giving lower microparticle counts. At $4^{\circ} \mathrm{C}$, a single centrifugation of $20 \mathrm{~min}$ at $12,000 \mathrm{~g}$, medium brake resulted in significantly lower microparticle counts compared to the double centrifugation (2000 $\mathrm{g}$, medium brake, followed by 12,000 $\mathrm{g}$, hard brake; $10 \mathrm{~min}$ each), in both donors (Table 2).

\section{Validation of urine processing protocol}

\section{Robustness}

Centrifugation deceleration. Following optimization, which showed a single centrifugation of $20 \mathrm{~min}$ at $12,000 \mathrm{~g}$, medium brake to be optimal, robustness was evaluated in terms of the effect of different brake speeds on centrifugation at $4^{\circ} \mathrm{C}$. Urine samples had significantly different microparticle counts with the three brake speeds, the number of microparticles decreasing with increasing brake speed, and microparticle-associated acceptance criteria were not met (Table 3). A pairwise multiple comparison showed the significant difference to be only between the highest and lowest brake speeds. The protocol was robust for different brake speeds for all other parameters, each of which was within the acceptance criteria limits, and was without significant differences for cystatin $\mathrm{C}$ and creatinine concentrations; 10 out of 331 detected metabolites were significantly different, giving a $97 \%$ rate of metabolites with nonsignificant differences. One of the significantly affected metabolites could be identified as glycine. With the hard brake giving lower microparticle counts (albeit not statistically significant compared to the medium brake), the hard brake was selected for the optimized protocol as it allows quicker processing times.

Centrifugation temperature. Robustness was also evaluated in terms of the effect of centrifugation at $4^{\circ} \mathrm{C}$ versus $21^{\circ} \mathrm{C}$. The protocol proved to be robust for all parameters, being within the acceptance criteria limits and without significant differences for microparticle counts, and cystatin C and creatinine concentrations, while two out of 310 detected metabolites were significantly different, giving a $99.4 \%$ rate of nonsignificant difference (Table 4).

\section{Reproducibility}

The methodology acceptance criteria in terms of microparticle counts were met for all three replicates in the reproducibility assessment (Table 5). Reproducibility acceptance criteria were met for all parameters; microparticle counts, cystatin $\mathrm{C}$ and creatinine concentrations limits, CV $<20 \%$, and nonsignificant differences in concentrations of $>95 \%$ of metabolites (Table 5). The protocol yielded 14 out of 413 detected metabolites (3.4\%), which were significantly different (metabolite results are available on request). The 20-min, $12,000 \mathrm{~g}$ centrifugation at $4^{\circ} \mathrm{C}$ with hard brake was validated as reproducible for urine collection.

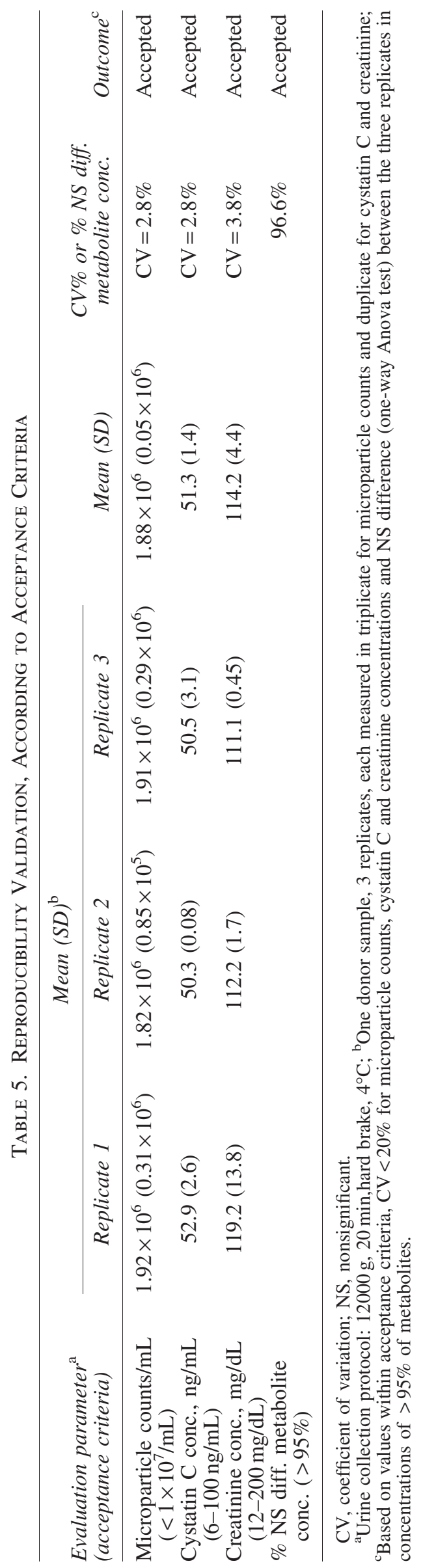


Table 6. Sample Processing Method Overview

\begin{tabular}{lc}
\hline Parameter & Urine sample \\
\hline Primary container type & $\begin{array}{c}\text { Urine collection cups, poly- } \\
\text { propylene, sterile }\end{array}$ \\
$\begin{array}{l}\text { Secondary container type } \\
\text { Precentrifugation delay }\end{array}$ & Maximum 3 hours at $4^{\circ} \mathrm{C}$ \\
between collection and & \\
processing & $12,000 \mathrm{~g}$; 20 min; $4^{\circ} \mathrm{C}$; high \\
Centrifugation & brake force \\
Postcentrifugation & Collect supernatant, homoge- \\
& nize and aliquot \\
Long-term storage & $-80^{\circ} \mathrm{C}$ \\
\hline
\end{tabular}

\section{Discussion}

The uncontrolled presence of microparticles in the context of identifying biomarkers is a potential confounder, and low microparticle counts are considered optimal. With our initial analyses showing that higher centrifugation speeds result in lower microparticle counts at RT, centrifugation at $4^{\circ} \mathrm{C}$ was performed at $12,000 \mathrm{~g}$, with the single centrifugation taking preference over the double in light of significantly lower microparticle counts. While two-step centrifugation is optimal for intact cell isolation (in the pellet of the first centrifugation), a single high-speed centrifugation gives lower microparticle counts, is more amenable to automation, is less time consuming, and is less sensitive to handling errors, making it the method of choice for urine processing when the intact cell fraction is not of interest for downstream use.

The method was robust overall for different brake speeds, although significantly lower microparticle counts were obtained with a hard brake, reflecting the fact that weaker braking and longer deceleration times favor significant release of microparticles into the supernatant. This suggests that a hard brake is optimal and highlights the importance of systematically reporting the brake speed. The protocol proved robust when comparing centrifugation at $4^{\circ} \mathrm{C}$ versus $\mathrm{RT}$, with all acceptance criteria met. The 20 -min centrifugation at $12,000 \mathrm{~g}$ at $4^{\circ} \mathrm{C}$ with hard brake was reproducible in terms of mean microparticle counts, cystatin $\mathrm{C}$ and creatinine concentrations within acceptable limits, with a CV less than $20 \%$, and a profile of metabolites with $>95 \%$ without significant differences. Where proteomic and metabolomic research is concerned, pre-processing and processing of samples at $4^{\circ} \mathrm{C}$ is considered essential. Not only does it minimize protein degradation due to protease activity, ${ }^{24-26}$ it also limits metabolite changes that can occur due to bacterial growth at $\mathrm{RT},{ }^{27}$ and potential microbial growth due to the nonsterile nature of urine. ${ }^{28}$ Glycine could be unambiguously identified and was found to be poorly reproducible.

Neither protease inhibitors nor other stabilizers were used in this protocol. It has been shown that polypropylene tubes without any preservative can be used for multipotency urine test strip analyses and particle counting when kept at $4^{\circ} \mathrm{C} .{ }^{29,30}$ It has also been shown that urinary proteins undergo rapid degradation when left at $\mathrm{RT}$, regardless of the presence of protease inhibitors which only have a protective effect within 2 hours of collection. ${ }^{31}$

Varying susceptibility of a range of urinary proteins to degradation under different storage conditions has been reported. Creatinine is stable for up to 2 years when stored at $-20^{\circ} \mathrm{C}$ or $-80^{\circ} \mathrm{C}$, while at $4^{\circ} \mathrm{C}$ it is stable for 30 days. ${ }^{32}$ Cystatin $\mathrm{C}$ is stable for 7 days at both $4^{\circ} \mathrm{C}$ and $-20^{\circ} \mathrm{C}$ and for $48 \mathrm{~h}$ at $20^{\circ} \mathrm{C}$, for up to three freeze/thaw cycles and at $\mathrm{pH}>5 .{ }^{33}$ It has recently been shown that post-centrifugation delays of up to 48 hours at either RT or $4^{\circ} \mathrm{C}$ do not have a significant impact on the levels of biomarkers of acute kidney injury (neutrophil gelatinase-associated lipocalin, interleukin-18, kidney injury molecule 1, liver-type fatty acid-binding protein). ${ }^{34}$ In order to prevent degradation of more sensitive molecules, a post-centrifugation delay of less than 2 hours at $4^{\circ} \mathrm{C}$, storage of urine supernatant at $-80^{\circ} \mathrm{C}$, and avoiding freeze/thaw cycles is recommended.

We provide here formal validation of the methodology for a urine processing protocol of a 20 -min centrifugation at $12,000 \mathrm{~g}$ at $4^{\circ} \mathrm{C}$ using a hard brake that is fit-for-purpose for the use of urine supernatant in proteomic and metabolomic analyses (Table 6). Because of the small number of samples used in our study, the power is limited and negative results should be interpreted with caution. The pellet can be used for DNA-based analyses such as genotyping ${ }^{35}$ or urinary metagenomics analyses. ${ }^{28}$ Microparticles in the supernatant can be isolated for further analyses by ultracentrifugation at a later stage, after storage at $-80^{\circ} \mathrm{C}^{21,36}$

Urine preanalytical conditions have been studied in specific proteomic methods including MALDI-TOF-MS, ${ }^{37}$ 2D-electrophoresis, ${ }^{4}$ SELDITOF MS, ${ }^{31}$ and LC-MS, ${ }^{38}$ showing that collection and processing variables can have a major impact on specific proteins and peptides. In this context, laboratories and biobanks operating under accreditation are advised to track and record preanalytical data systematically using the Standard PREanalytical Code (SPREC), ${ }^{39,40}$ while freeze-thaw cycles and other treatments (e.g., use of protease inhibitors, stabilizers) should be reported in the Laboratory Information Management System. Biobanks and clinical laboratories facing accreditation requirements and/or processing biospecimens for clinical biomarker research can implement the urine preparation methods presented here with reference to this publication.

\section{Acknowledgments}

We thank Sarah MacKenzie, PhD, for medical writing assistance (funded by IBBL) and William Mathieson for critical reading of the manuscript.

\section{Author Disclosure Statement}

No competing financial interests exist.

\section{References}

1. Bowers J. CAP takes the reins on biorepository accreditation. CAP Today Coll Am Pathol. October 2012. http:// www.cap.org/apps/cap.portal. Reference resources and publications/CAP Today/2012 Articles.

2. Technical Standard NF S96-900. [Quality in the Biology Resource Centers (BRC) - Management system of a BRC and quality of the biological resources] in French. September 2011.

3. Ammerlaan W, Trezzi J, Lescuyer P, et al. Method validation for preparing serum and plasma samples from human blood for downstream proteomic, metabolomic and circulating nucleic acid-based applications. Biopreserv Biobank 2014;12:269-280.

4. Lafitte D, Dussol B, Andersen S, et al. Optimized preparation of urine samples for two-dimensional electrophoresis and initial application to patient samples. Clin Biochem 2002;35:581-589. 
5. Latterich M, Abramovitz M, Leyland-Jones B. Proteomics: New technologies and clinical applications. Eur J Cancer 2008;44:2737-2741.

6. Sharma K, Karl B, Mathew AV, et al. Metabolomics reveals signature of mitochondrial dysfunction in diabetic kidney disease. J Am Soc Nephrol 2013;24:1901-1912.

7. Fanos V, Locci E, Noto A, et al. Urinary metabolomics in newborns infected by human cytomegalovirus: A preliminary investigation. Early Hum Dev 2013;89 Suppl 1:S58-61.

8. Nair H, Woo F, Hoofnagle AN, et al. Clinical validation of a highly sensitive GC-MS platform for routine urine drug screening and real-time Rreporting of up to 212 drugs. J Toxicol 2013;2013:329407.

9. Kim JW, Ryu SH, Kim S, et al. Pattern recognition analysis for hepatotoxicity induced by acetaminophen using plasma and urinary $1 \mathrm{H}$ NMR-based metabolomics in humans. Anal Chem 2013;85:11326-11334.

10. Favé G, Beckmann M, Lloyd AJ, et al. Development and validation of a standardized protocol to monitor human dietary exposure by metabolite fingerprinting of urine samples. Metabolomics 2011;7:469-484.

11. International Society for Biological and Environmental Repositories (ISBER). 2012 Best Practices for Repositories. Collection, storage, retrieval and distribution of biological materials for research. Third edition. Biopreserv Biobank 2012;10:79-161.

12. Canadian Tumor Repository Network. Standard Operating Procedures. https://www.ctrnet.ca/operating-procedures. Accessed February 2014.

13. Guerin J, Murray D, McGrath M, et al. Molecular Medicine Ireland Guidelines for Standardized Biobanking. Biopreserv Biobank 2010;8:3-63.

14. Lehmann S, Roche S, Allory Y, et al. [Preanalytical guidelines for clinical proteomics investigation of biological fluids] in French. Ann Biol Clin (Paris) 2009;67:629-639.

15. Thomas $\mathrm{CE}$, Sexton $\mathrm{W}$, Benson $\mathrm{K}$, et al. Urine collection and processing for protein biomarker discovery and quantification. Cancer Epidemiol Biomarkers Prev 2010;19:953-959.

16. Human Kidney and Urine Proteome Project (HKUPP). Standard Protocol for Urine Collection and Storage (applicable for the analysis of soluble urine proteins; not for exosome analysis). Normal Urine (Adults). http://www.hkupp.org/Urine\%20 collectiion\%20Documents.html. Accessed February 2014.

17. Medeiros M, Sharma VK, Ding R, et al. Optimization of RNA yield, purity and mRNA copy number by treatment of urine cell pellets with RNAlater. J Immunol Methods 2003;279:135-142.

18. Gaydos CA, Quinn TC. Urine nucleic acid amplification tests for the diagnosis of sexually transmitted infections in clinical practice. Curr Opin Infect Dis 2005;18:55-66.

19. Pisitkun T, Shen R-F, Knepper MA. Identification and proteomic profiling of exosomes in human urine. PNAS 2004;101:13368-13373.

20. Hayward RM, Kirk MJ, Sproull M, et al. Post-collection, pre-measurement variables affecting VEGF levels in urine biospecimens. J Cell Mol Med 2008;12:343-350.

21. Zhou H, Yuen PST, Pisitkun T, et al. Collection, storage, preservation, and normalization of human urinary exosomes for biomarker discovery. Kidney Int 2006;69:1471-1476.

22. Uchida K, Gotoh A. Measurement of cystatin-C and creatinine in urine. Clin Chim Acta 2002;323:121-128.

23. Hiller K, Hangebrauk J, Jäger C, et al. MetaboliteDetector: Comprehensive analysis tool for targeted and nontargeted GC/ MS based metabolome analysis. Anal Chem 2009;81:3429_ 3439.
24. Yan L, Borregaard N, Kjeldsen L, et al. The high molecular weight urinary matrix metalloproteinase (MMP) activity is a complex of gelatinase B/MMP-9 and neutrophil gelatinaseassociated lipocalin (NGAL). Modulation of MMP-9 activity by NGAL. J Biol Chem 2001;276:37258-37265.

25. Quinto BM, Juliano MA, Hirata I, et al. Characterization of a prolyl endopeptidase (kininase) from human urine using fluorogenic quenched substrates. Int J Biochem Cell Biol 2000;32:1161-1172.

26. Schauer-Vukasinovic V, Langen H, Giller T. Detection of immunoreactive napsin $\mathrm{A}$ in human urine. Biochim Biophys Acta 2001;1524:51-56.

27. Saude EJ, Sykes BD. Urine stability for metabolomic studies: effects of preparation and storage. Metabolomics 2007;3:19-27.

28. Lewis DA, Brown R, Williams J, et al. The human urinary microbiome; bacterial DNA in voided urine of asymptomatic adults. Front Cell Infect Microbiol 2013;3:41.

29. Froom P, Bieganiec B, Ehrenrich Z, et al. Stability of common analytes in urine refrigerated for $24 \mathrm{~h}$ before automated analysis by test strips. Clin Chem 2000;46:1384-1386.

30. Kouri T, Malminiemi O, Penders J, et al. Limits of preservation of samples for urine strip tests and particle counting. Clin Chem Lab Med 2008;46:703-713.

31. Papale M, Pedicillo MC, Thatcher BJ, et al. Urine profiling by SELDI-TOF/MS: Monitoring of the critical steps in sample collection, handling and analysis. J Chromatogr B Analyt Technol Biomed Life Sci 2007;856:205-213.

32. Spierto FW, Hannon WH, Gunter EW, et al. Stability of urine creatinine. Clin Chim Acta 1997;264:227-232.

33. Herget-Rosenthal S, Feldkamp T, Volbracht L, et al. Measurement of urinary cystatin $\mathrm{C}$ by particle-enhanced nephelometric immunoassay: Precision, interferences, stability and reference range. Ann Clin Biochem 2004;41:111-118.

34. Parikh CR, Butrymowicz I, Yu A, et al. Urine stability studies for novel biomarkers of acute kidney injury. Am J Kidney Dis 2014;63:567-572.

35. Vu NT, Chaturvedi AK, Canfield DV. Genotyping for DQA1 and PM loci in urine using PCR-based amplification: Effects of sample volume, storage temperature, preservatives, and aging on DNA extraction and typing. Forensic Sci Int 1999;102:23-34.

36. Gonzales PA, Zhou H, Pisitkun T, et al. Isolation and purification of exosomes in urine. Methods Mol Biol 2010;641:89-99.

37. Calvano CD, Aresta A, Iacovone M, et al. Optimization of analytical and pre-analytical conditions for MALDI-TOFMS human urine protein profiles. J Pharm Biomed Anal 2010;51:907-914.

38. Court M, Selevsek N, Matondo M, et al. Toward a standardized urine proteome analysis methodology. Proteomics 2011;11:1160-1171.

39. Betsou F, Lehmann S, Ashton G, et al. Standard preanalytical coding for biospecimens: Defining the sample PREanalytical code. Cancer Epidemiol Biomarkers Prev 2010;19:1004-1011.

40. Lehmann R, F. Guadagni, H. Moore, et al. Standard preanalytical coding for biospecimens: Review and implementation of the Sample PREanalytical Code (SPREC). Biopreserv Biobank 2012;10:366-374.

Address correspondence to: Dr. Fay Betsou Integrated BioBank of Luxemburg 6 rue Nicholas Ernest Barblé Luxembourg L-1210 Luxembourg

E-mail: fay.betsou@ibbl.lu 